\title{
Journal of Psychiatric and Mental Health Nursing
}

\section{Accepted for publication July 2017}

\section{Title}

Unlocking stories: older women's experiences of intimate partner violence told through creative expression

\section{Authors}

(1)Dr Julie McGarry, Associate Professor, School of Health Sciences, University of Nottingham. A Floor South Block Link, Queens Medical Centre, Nottingham NG7 2HA, UK

Tel: $0044+(0) 1158230516$

Email: http://www.nottingham.ac.uk/healthsciences/people/julie.mcgarry

(2)Dawn Bowden, Independent Drama Practitioner.

Email: dawn.bowden@sky.com 


\section{ABSTRACT}

\section{INTRODUCTION}

Intimate partner violence (IPV) exerts a detrimental impact on the lives and health of all who experience abuse. This includes both physical and mental health and wellbeing. The experiences of older women however may be different and these differences may not be recognised or accounted for within existing care provision.

\section{AIM}

To explore the impact of IPV on the lives and health of older women told from the particular perspective of older women themselves as these accounts are largely absence from existing IPV discourse.

\section{METHOD}

An arts based research approach with five older women survivors of IPV through the co-development and organisation of an arts based workshop. The workshop essentially encompassed four main arts strands and included the creation of clay models and poetry.

\section{FINDINGS}

The findings of the study highlight the significant impact of IPV on the lives, mental health and wellbeing of older women. This included feelings of social isolation, inability to trust others and a loss of self-identity. 


\section{DISCUSSION}

IPV is a global issue and as such of relevance for those working in healthcare contexts beyond the UK. While there is a growing body of evidence surrounding IPV and older women this has largely been presented through researcher led accounts and as such the narratives of women themselves may not have been adequately acknowledged. Unlike much of the existing evidence, the present study has explored the particular situation for older women as told through creative expression and their own stories of survivorship. In the present study the fluidity of the potential materials available in the workshops meant that both the representations through which the women spoke and the primacy of their voices, over those of more traditional researcher accounts, was in evidence throughout.

\section{IMPLICATIONS FOR PRACTICE}

Mental health nurses and practitioners are often on the front line for care and support for older client populations. IPV across the life span is a global issue for healthcare practitioners. It is anticipated that the findings of this study will provide the mechanism through which mental health nurses and other practitioners may reflect on older women's accounts of IPV as told by older women in the present study in their own words. Reframing from dominant professional discourse to personal narrative is central to person-centred approaches and is central to contemporary practice. Ultimately this has the potential to improve the effectiveness of care provision and support.

\section{RELEVANCE TO MENTAL HEALTH NURSING}


The findings presented in this paper have the potential to provide a powerful tool for those working within mental health contexts and healthcare professionals working with older populations more generally to consider both the hidden nature of IPV and the ways in which IPV can significantly impact on mental health and wellbeing in later life.

\section{ASSESSABLE SUMMARY}

\section{WHAT IS KNOWN ON THE SUBJECT}

- Intimate partner violence (IPV) impacts significantly on the lives and health of those who experience abuse

- The impact of IPV exerts a detrimental impact on mental health as well as physical health but this is often not recognized by professionals

\section{WHAT THE PAPER ADDS TO EXISTING KNOWLEDGE}

- This paper highlights the impact of IPV on the lives and health of older women from the perspective of older women themselves

- The approach taken to the study illuminates the ways in which older women describe their experiences within the broader narratives of their experiences

- The present study has explored the particular situation for older women as told through creative expression and their own stories of survivorship.

\section{IMPLICATIONS FOR PRACTICE}


- Nurses and other healthcare professionals need to be aware of the enduring impact of IPV for older women, particularly within the context of mental health

- Those working with older women also need to be alert to the potential barriers to disclosure and disjuncture between professional dialogue and personal narrative 


\section{INTRODUCTION AND BACKGROUND}

Intimate partner violence (IPV) is now acknowledged as a global health concern and a wider issue for society in general (World Health Organisation, (WHO) 2016). The detrimental impact on both physical and mental health status for those who experience IPV, and their wider family members, is also widely recognised. While it is acknowledged that IPV is experienced by both men and women, violence against women is more commonly perpetrated by an intimate partner or ex-partner (WHO, 2012). IPV is not exclusively defined by age however and the effect of IPV on the lives and health of older women who have experienced abuse has often not been adequately acknowledged within the wider IPV discourse overall (Nägele B, Bohm U, Toth O, Goergen T. 2011).

This is arguably a significant oversight as while IPV exerts a significant impact on the lives and health of all of those who experience abuse there may be a number of ways in which the experiences of IPV for older women may be different to that of their younger counterparts (Hightower J, Smith M, Hightower H. 2006). For example, there may be perceptions among older women regarding the societal context of IPV including the 'privacy of the home' and feelings of shame in reporting IPV (Band-Winterstein and Eisikovits 2010), Beaulaurier RL, Seff LR, Newman FL, Dunlop B. 2006) and a lack of awareness of the support available for those seeking to leave abusive relationships (McGarry J, Simpson C, Mansour M. 2010). Moreover, there has also been limited recognition across a number of professional services surrounding IPV as an issue for older women and the consequent blurring of the boundaries between IPV and elder abuse ( Scott M, 
McKie L, Morton S, Seddon E, Wosoff F. 2004). This has further added to the invisibility of IPV for women in later life.

The consequences of IPV on the health of older women are far reaching and include both immediate and longer term physical health outcomes from injuries sustained as a result of IPV (McGarry, et al. 2010). For older women who have experienced IPV there are also significant and pervasive mental health consequences that can be experienced over a prolonged period of time and these include anxiety and depression and substance misuse (Dutton MA, Green BL, Kaltman SI, Roesch DM, Zeffiro TA, Krause ED. 2006). However, for older women the hiddenness of IPV generally may further compound their invisibility when presenting to health services as result of experiencing mental health problems. Women who have experienced IPV have spoken about how healthcare professionals have 'pathologized' their mental health symptoms rather than exploring the underlying reasons for their presentation (Humphreys \& Thiara 2003). This is further illustrated in the literature whereby studies that have examined IPV within the context of mental health have either excluded older women ( Ellsberg M, Jansen HA, Heise L, Watts CH, Garcia-Moreno C. 2008) or have not distinguished the age of study subjects in the wider study sample ( Trevillion K, Oram S, Feder G, Howard LM. 2012).

Despite a growing awareness and engagement among some researchers regarding the particular issues and experiences of IPV for the mental health and wellbeing of older women, there is still little in terms of available resources for professionals and organisations who are working in this context which explicitly focus on mental health, IPV and older women's experiences. There also appears 
to be a paucity of available evidence within the existing literature that has sought to explore this from the particular perspective of older women in their own words.

This paper reports the findings of an arts based project with older women as survivors of IPV to explore their experiences of survivorship and the impact of IPV on their mental health and wellbeing. In so doing we present the artefacts that were created by women participants during the workshops.

\section{THE STUDY}

The overarching aim was to explore the impact of IPV on the lives and health of older women told through creative expression from the particular prospective of older women themselves.

\section{STUDY DESIGN}

The use of an arts based research approach to the workshop study design

There are traditionally two main paradigms or approaches to the research endeavour and these are broadly described as positivism (quantitative methodologies) and interpretive (qualitative methodologies). The former derived from the natural sciences and the latter developing from the recognition of the differing meaning and nature of 'knowledge' within the social sciences and thus its possibilities for acquisition (Bryman, 2004). Latterly however, even traditional qualitative approaches have elicited a degree of criticism in terms of their limitations to fully appreciate the 'constant movement' of social life. For example, Foster (2007) describes her rationale for using an arts based research approach as taking 'into account a host of standpoints as well as capturing the 
complexities and not least, the beauty of life....the research process is every bit as key as the resultant findings' (p363). Leavy (2015) further supports this approach in describing the 'synergies between artistic and qualitative practices' (p18). For example, highlighting that both seek to provide sensitive accounts of people, their situations and their lives in order to challenge dominant discourses and expose bias. Importantly, arts based research approaches offer a medium thorough which participants may feel empowered to share their experiences through their own accounts. This is of central importance in the present study where the voices of older women who have experienced IPV have largely been unheard.

Within arts based research practice there are a number of different approaches that may be taken and these include poetry, music, visual art and narrative enquiry. Poetry for example, the method chosen as part of the present study has been described as 'rejecting static or unitary meaning' (Leavy, 2015 p92) and instead 'resonates more fully with the way identity is created, maintained and altered through our narratives and interactions' (Faulkner, 2009, p99). This approach therefore was in keeping with the overarching aims of the study.

The use of arts based research approaches as a way of exploring the lived experience of individuals therefore is also now recognised both within postmodern qualitative research methods (Foster, 2007) and within the context of informing professions in everyday practice (Crawford, P., Brown, B., Baker, C., Tischler, V., Abrams, B. 2015). It has been argued that the value of personal narrative for example, lies in the reframing of the discourse of health and illness from one which is professionally dominated to one which holds the most 
meaning for the individuals concerned (Frank, 2013). Furthermore, as Crawford et al (2015) suggest:

The foundation of healthcare practice, across all disciplines should be based on hearing, respecting, valuing and responding to people's experiences, interpretations, relationships, priorities, emotions and life stories (Crawford, et al. 2015. P53).

As such, an arts based research approach formed the basis of the study workshop. In practice the project team, i.e. the older women as IPV survivors, a qualified drama practitioner and members of the University of (name) research team, worked together to explore the experiences and impact of IPV from the particular perspective of the women themselves. The one day workshop was cofacilitated by members of the research team and an independent drama practitioner (co-author of this paper). We chose a group workshop approach rather than individual focused sessions as wished to provide a supportive and creative space where women could work together in a group activity. The workshop was situated in a neutral venue that had all of the required facilities and was also accessible for all participants in terms of personal safety and anonymity.

\section{PARTICIPANT SELECTION}

Purposive sampling was utilized to recruit participants to the study. Older women as survivors of IPV were invited to take part in the project through a local IPV specialist women's organisation in one region of the United Kingdom (UK). A poster style invitation advertising the details of the study was distributed 
within the women's organisation with the contact details of the lead researcher for women who wished to discuss the possibility of taking part in the workshops in more depth. For personal safety reasons, for example the poster advertised the date of the workshop, the information was only distributed through the IPV specialist organisation. In total, five older women responded to the poster invitation and following the receipt of further information, agreed to participate in the project (age range 50 - 80 years). The limited number of women who responded to the invitation may be explained in part by the approach utilised, however, as safety of participants was paramount this approach was felt to be most appropriate. Secondly, the number of participants may also reflect the 'hiddenness' of IPV, particularly among older women as encountered in previous studies undertaken in this field (McGarry, et al. 2010). At the time of the project four of the women were no longer in abusive relationships. One woman had been in receipt of mental health services. We included the age range of $50+$ years as there are a range of age parameters applied across health and social care, but for IPV services 50 years and over often denotes a different service approach for example, refuge facilities specifically for $50+$ women. The project was undertaken between January and December 2015.

\section{Ethical approval}

Ethical approval was granted to undertake the study through the (name of institution) ethics committee. In addition to consideration of the general issues surrounding consent and confidentiality the team were also cognisant of the sensitivity of the subject area and the potential vulnerability of the participants in terms of retelling their stories and personal safety. A support worker from a local specialist IPV organisation formed part of the project team and were able to 
advise on the project generally and also to attend the workshops in order to provide support if needed. In addition, the specialist worker also contacted the workshop participants after the workshops as part of supportive follow-up. Researching sensitive topic areas may also impact on those involved in the research and so the team also built in dedicated debriefing time at the end of each workshop day. Finally, throughout the study the women were aware that the poems and artefacts created remained their own. As such, they could choose whether they wished to share these with the team or keep them for themselves. The ownership of the artefacts was also explicitly written into the study information sheets that the women received prior to taking part in the workshop.

\section{METHODS}

\section{Data collection}

\section{Our overarching approach to the workshops}

Survivors of any and all abuse become very good at anticipating mood of others, looks, actions, all of it in an effort to survive.

Believing that if we can be agreeable, be compliant and loving, do things how they want, that we will be safe.

This becomes our way of life (Darlene Ouimet, Emerging from Broken)

\section{Letting go...}

The above quote informed the project teams overarching philosophy and approach to the workshop facilitation. It was felt that this quote was particularly pertinent as many women who have experienced IPV may not feel that they anything to offer or that their opinions and thoughts have little value. In 
practice, 'letting go' meant jettisoning any notions among the project group of the need to obtain a particular 'result' from the workshop. Therefore the aim was to facilitate a participant led environment where the women could express themselves freely.

\section{Data analysis and presentation of findings}

The composition of the workshops is described in detail below and essentially encompassed four main strands. Data analysis and presentation of the findings in the current study are presented in contrast to more traditional methods of qualitative enquiry which as it has been argued by a number of commentators may be disempowering for participants. For example, the process of data 'abstraction' from the original context of the narrative, through the loss of participant control in terms of what is or is not included in the findings, and through the complexity of academic/professional language which may exclude wider audiences (Foster 2007). Through the medium of poetry and creation of clay models the women in the study were able to develop their own stories which as Foster (2007) highlights, reflecting on experiences as a researcher working within arts based research, 'is a very different practice from that of the researcher selecting (methodologically or otherwise) snippets from various interviews and piecing them together to tell a particular tale from his or her own perspective' (p371). Therefore, rather than distilling the findings of the workshops we have chosen to present all of the poems and artefacts in their original format.

\section{Findings}

\section{Creating a Survivor: the use of 'persona'}


At the commencement of the workshop we utilized a persona approach as a first group exercise. A persona is a fictional person created by a particular group where the persona has particular characteristics or attributes. This approach has been utilized in a number of disciplines previously (Nilsson, A., Fältholm, Y., Abrahamsson, L. 2010). We used this approach as the women had not worked together before and it was felt to be non-threatening, enabling the group to begin to work together without feeling that they needed to disclose personal information about themselves. In practice creating a survivor entailed one of the project team (author) lying down on a large piece of paper. We invited someone to draw around this person. When they had finished the project team member stood up and we were left with an outline shape. We explained that this was the outline of a survivor of IPV. The women decided if she was in the relationship or away from the relationship. All the women said that she was in the relationship. We asked the women to name her in order to disassociate themselves from her. They named her Rachel. We asked the women 7 questions about Rachel. The questions, developed by (the drama practitioner), were informed by her previous work with hard to reach community groups (Reference author):

- What she knows about herself?

- What she thinks about herself

- What she thinks others might think?

- What she thinks other might say?

- What she hopes for?

- What she hasn't discovered? What doesn't she know?

- What else? 
Initially the women in the workshop gave their answers as if they were Rachel. However some of the women very quickly moved on to their own experiences. For example, one woman said that Rachel was worried that people would not like her partner if they knew the truth (that he was the perpetrator of abuse). She then went on to tell us that this was the case with her situation. She told us that people liked her partner and she had not wanted them to know the truth in case they wouldn't like him anymore. During the discussion the women in the group identified a number of key themes associated with Rachel and these included; 'not being believed', 'lacking the financial independence to leave', the health impact of abuse including physical symptoms for example, 'a lack of energy' and mental health issues 'feeling depressed', 'blames herself', 'it's her fault' and 'feels stupid for letting it happen'. The women said that Rachel 'wanted the abuse to stop' and that she 'worried about losing her family if anyone found out'. Facilitating an exercise like this early on in the session enabled the women to discuss Rachel, potentially using their own experiences as reference. In practice it worked especially well in terms of 'breaking the ice' within the group as all of the women were able to discuss the issues raised and were supportive of each other. Not all the women moved on to talking about their own experiences but that didn't matter because we hadn't asked them to.

\section{Cut Up Poem}

The women worked in 2 small groups. We explained that we would like the women to respond to a series of questions with no more than a one line written answer. We asked the women in the group to write down their answers and then to tear off each of their answers as slips of paper to be folded and placed in the 
centre of our workspace table. We asked the following questions about surviving:

- What is surviving?

- What does it feel like?

- Think about a survivor...what do they look like?

- What do they hear?

- What do they see?

- What do they say?

At the end of the exercise each group had a series of paper slips in the centre of the table. The women then read out the individual contributions and then chose $8-10$ in order to create a poem. They did this collectively and with mutual respect for each other's opinions. They then were invited to edit the poem if they wanted to. The women created the poems 'One day at a time' and 'Silent'.

\section{One day at a time}

A weak person who ceases to exist.

Overwhelmed, anxious, depressed, hopeless and confused.

Trying to stay safe, financially and emotionally holding it all together.

Just getting through another day living one day at a time.

Worried, sad, wishing things could have been better.

Wondering if she would make the right decision. 
She is glad to be out of it.

Sorry.

\section{Silent}

I think about surviving. I am trapped in this way to live my life. Dark dwells around me.

I hear sounds like a knife scratching or chains are rattling.

Waking up in the morning breathing.

Surviving is living a day at a time.

The women with pale skin and black eyes.

She perhaps laughs a bit.

Peace and silence birds singing.

Smiley faces things around me.

My heart beating.

The woman does not like to talk, she is silent.

Happier, she has done something for herself

\section{Clay Models}

During the workshop we asked the women participants if they would like to use some of the arts materials that we had taken along to the workshop. The women chose to work with clay to model 'Surviving'. Each of the women interpreted this one word in very different ways. Again by not having an expectation and leaving 
the invitation open for interpretation the women produced very different clay models. Five clay models were created during the workshop day:

Nightmare man

Tears in my heart

Trapped

Be yourself

Bowl of lives goods

After the women had created their models they were invited to talk a little about what they had created and why. Nightmare man depicted one survivor's expartner and the perpetrator of IPV. She explained that she had chosen to use small sharp sticks for the hands and mouth as this represented his verbal and physical violence. She stated that she had called the model 'nightmare man' as he 'still scared her all these years later'. If she saw him in the street she would 'jump on a bus [to get away from him] and go to places she didn't want to go'. Tears in my heart was a clay model of a broken heart and the participant who had made this model described the mental and physical pain of both being in and leaving an abusive relationship and of not being able to trust others. This participant had also created the Trapped model which depicted a woman crouching in a cage which had been decorated with flowers. The participant spoke of the veneer of a 'normal married life' but that beneath the veneer how she had been trapped and the impact that this had exerted on her mental health and wellbeing. Be yourself was a model of a Buddhist monk and the participant who created this model spoke of the 'lies' of living in her abusive relationship, how she felt unworthy and 'not good enough' and unable to trust people. She spoke of her perceptions of Buddhist monks as not judging people, of being open and honest and accepting. The bowl of lives goods was described by the 
participant who made it as trying to make sense of her situation and of trying to rebuild her life after she had left the abusive relationship.

\section{The Individual Poems}

We laid out a stone, a crumpled tissue, a key, a candle and a ball of string. We asked the women to choose an object. We then asked them to answer a series of questions AS the object. Questions focussed on the object in relation to their functionality, purpose, where they had been before where they are now and how they would be remembered. These objects were chosen as could not lead one way or the other. For example, a key can open and close, be lost, be found, a rock can be perceived as hard and immovable or strong and beautiful. The same with the other objects. Relating this back to the 'lack of expectations' we tried to make sure that the objects were not leading in any way. It was only when the women shared their poems that they became aware that they had written a poem. This approach was drawn from the earlier work that (drama practitioner) had facilitated with poet and playwright Kevin Fegan (2016) who used the group poem idea successfully with a group of hard to reach young people. The poems created are below:

\section{The Key}

I am a Metaphor for some of the most important things in life.

I am a bit cold but I am shiny and new.

I have learned to stop comparing myself as a criticism and only as a tool for learning from.

I would hope that the others may only seek to understand me rather than compare with me. 
If they see me shining then it's great.

I would like to find the secret lock to open the right doors to my future.

I dream of a shiny new lock to fit with as a pair, to open a whole world of dreams.

I am scared of getting lost, not fitting or finding my purpose.

The rock next to me is solid and natural. It can be formed with the weather and seasons.

I am man made and look for my natural state.

I was waiting to be moulded, pressed and shaped into my current form.

I can be worn down or melted and reshaped from my natural shape or current form.

I feel like I'm revisiting my past life but realise I am still in the same shape, a little vulnerable but still can shine.

I am here now to unlock a little bit more.

The secret to unlocking your heart is with a shiny new key.

\section{I am string}

I am string.

Wound up.

Not as strong as some, not as thick as others!

Others think I hide myself in layers.

To be unravelled gently and not tied up in knots.

Being free and not bound.

Getting burned!

I can hurt me, I can soothe me.

I was part of a living thing. 
Ready to be useful.

To make people think!

Used by many-everybody's saviour.

\section{Tissue}

I am a tissue / handkerchief.

Tired and wet.

Not so strong and keep breaking up.

They think I am weak and unreliable.

I would like to be strong like the others and trust myself.

It dreams about the past, what's happened how frightened it was.

What is going to happen in the future?

I feel it is strong and plenty of it.

I was in a box.

On my own lonely, tired and wet.

\section{The Rock}

I am a stone (a rock).

I am absorbing spring sunshine and warming up in a daytime.

I am strong and solid inside and warm when the weather is sunny, I am eternity.

They think I am cold, ugly and a bit of dangerous.

I would like to be a part of a wall of a castle.

I dream about a butterfly sitting on me enjoying sunshine.

I am scared of being demolished (broken) by a big hammer. 
I feel that key is much more important, intelligent and useful than I am.

Before I was in the deep lake (floor) now I feel dry and enjoying a lot of fresh air and sunshine.

I am here because a fate changed my placement.

Epitaph will be written on me. I am eternity.

We have included the following reflection as we feel that is provides a brief insight into the complexity and sensitivity that is needed when working with survivors of IPV. It also highlights that as reflective practitioners, our experiences of the workshops and of hearing women's stories of surviving will stay with us for a long time and will help to shape our future practice.

\section{A personal reflection by (drama practitioner)}

One of the women in the group was still in an abusive relationship. She sat on the periphery of the group and when she did speak, she was very quiet. A couple of times she approached me in the breaks. The first time it was to add something to Rachel. The second time she told me a little bit more about herself and her abusive childhood. She seemed more comfortable speaking away from the group. The first clay model she made was of a hand. The other women in the group told her they thought it was amazing. I do not know if it was this focus and attention that then prompted her to fold the hand back into a ball of clay again, but for whatever reason, she did. It was only when I was clearing up that we noticed she had made another clay model. Very tiny and barely visible sitting on the table were two delicate rings linked together. One was red and one white. 
I cannot be sure that she left this for us to find. However it is interesting that she chose to leave this delicate barely visible representation of 'surviving' intact.

\section{DISCUSSION}

The aim of the present study was to explore the impact of IPV on the lives and health of older women told from the particular prospective of older women themselves. This study was undertaken in light of the recognised paucity of published evidence generally about the experiences of older women within the particular context of mental health (McGarry et al. 2016). Survivors of IPV do not represent a homogenous group and while there may be some generic features of IPV, the experiences of older women are significantly different to those of their younger counterparts in many respect. Due to historical societal norms for example, older women may feel more reticent about disclosing abuse in response to notions of privacy within the home alongside an absence in the past of services to support survivors of IPV (McGarry et al. 2010, SafeLives, 2016).

The findings of the present study have highlighted the profound long term impact of IPV that was felt by the older women and the ways in which this pervaded their everyday lives. In the present study for example, listening to and reading the poems One day at a time' and 'Tissue' highlight the women's descriptions of being 'not so strong and keep breaking up' and 'overwhelmed, anxious, depressed, hopeless and confused'. While one participant as highlighted earlier, during clay modelling, used the metaphor of a beautifully decorated cage and the title 'Trapped' to describe the isolation and powerlessness that she felt alongside the hiddenness of the abuse to those outside of the relationship. The feeling of being 'trapped' for older women in an abusive relationship has been 
identified elsewhere within the existing literature with a number of authors describing older women's feelings of shame and societal norms and beliefs that 'marriage was for life' which may make leaving an abusive relationship seem impossible (Beaulaurier, et al. 2007). However, in the present study participants were, through their rich narratives, able to contextualise how they had experienced 'powerless' and 'feeling trapped'. In the present study the same participant went on to describe how her experience had affected her significantly in terms of longer term mental ill-health in the sense that she had lost 'all sense of identity', doubted herself and was unable to trust others. The loss of trust was an enduring theme within the workshop, although expressed in different ways. For example, while 'Nightmare Man' depicted physical and emotional violence, the participant also spoke of not being able to trust others to help her if the perpetrator approached her while she was out shopping. For this participant, the loss was also felt through the imposed isolation and 'loss' of family as the perpetrator had prevented her from having contact with her children and she was only recently able to re-engage with her family. Loss was also felt through the loss of years during adulthood 'wishing things were better' and as expressed through the 'bowl of life's goods' the sense of trying to regain some enjoyment outside of the abusive relationship. The concept of loss is consistent with existing literature with Buchbinder \& Winterstein (2003) describing how older women felt a 'sense of loss' after the relationship had ended and the impact that this exerted on their emotional health and wellbeing. The participant who created the 'Buddhist Monk' also spoke of how she 'didn't feel good enough' and that this feeling was still with her even though she had left her abusive partner many years ago. Through discussions it was also clear that irrespective of age, the women shared many similar experiences and feelings. Low self-esteem and 
the sense of 'needing to rebuild self' for older women after leaving a relationship has also been described elsewhere and importantly for practitioners again reinforces the need to recognise that although the experience of IPV may be historical the longer term mental health consequences remain (McGarry J, et al. 2016). For practitioners, this final point is a valuable observation in terms of seeing beyond the 'mask of old age' that has historically inhibited older women's visibility in terms of recognition and access to support.

The configuration of health care services may differ across international boundaries, however IPV is now clearly recognised as a global health issue and a concern of all healthcare professionals (WHO, 2016). While there is a growing body of evidence with regard to the recognition of IPV as a significant health issue for older women - and distinct from elder abuse - this is still relatively limited if compared to that of younger groups of women (SafeLives, 2016, Lundy \& Grossman, 2009). Moreover, due to the nature of historical societal structures, limited IPV services and personal experiences, older women may be reticent to disclose abuse and/or further isolated in terms of access to services and support (McGarry et al. 2010). This study resonates with the existing international literature in acknowledging the impact of IPV for older women. However, the approach adopted in the present study also highlights the need for mental health nurses and healthcare professionals to be alert to both the existence of IPV in the lives of older women and also illuminates the often hidden yet pervasive impact in later life.

Understanding IPV experience from the perspective of older women, as described in the present study may also alert practitioners not only to the potential consequences of IPV but also to the potential isolation and paucity of 
familial and support mechanisms that are available in later life as a result of earlier abusive relationships.

\section{STUDY STRENGTHS AND LIMITATIONS}

In the present study the use of a participatory arts based research approach was viewed strongly as a positive experience by those who attended the workshops. For example, the women participants' spoke of the how they valued being able to share their experiences in a supportive environment, to know that other women had experienced similar feelings and that they were not alone. Importantly, the fluidity of the potential materials available to facilitate workshop discussions meant that both the representations through which the women spoke and the primacy of their voices, over those of more traditional researcher accounts, was in evidence throughout. In addition, for us as a group of women sharing our experiences, the workshops were highly valued by both participants and researchers.

This was a small scale study undertaken with five older women within one specific geographical location and as such there are potential limitations in terms of the transferability of the findings. As noted in the earlier 'personal reflection' the woman who was, at the time of the study, in an abusive relationship remained at times at the periphery of the group. As such, her experiences may not be fully acknowledged in the presentation of the findings. The support worker, alongside the research team, also participated in some of the group activities for example, the clay modelling. This may be viewed as a possible limitation - however, the artefacts were not included in the study and the nature of the workshop meant that working together as a group during the activities arguably facilitated a more inclusive and less formal environment for 
participants. It is also recognised that recruitment of older women to the study was potentially limited by the approach used. However, the safety of the women was paramount throughout and while we acknowledge that this was a small study sample, the findings arguably provide a valuable and additional contribution to the existing evidence base surrounding the impact of IPV in later life told by older women themselves.

\section{CONCLUSION AND IMPLICATIONS FOR PRACTICE}

The overarching aim of the project was to utilise an arts based research approach to explore the impact of IPV on mental health and wellbeing of older women. The women themselves developed the poems and clay models and had chosen the medium through which to work - we had also taken other materials along to the workshop so that women could decide on the day. Presenting the findings in the form of the artefacts that were created during the workshop enabled the women in the study to narrate their experiences in their own words. We feel that this has been a strength of this initiative in that the voices of survivors have taken precedence over more traditional professional or academic accounts as previously described. Facilitating older women participants to use their own words was also of central importance and as identified earlier the language that women use to describe their experiences does not necessarily concur with professional discourse.

Mental health nurses and practitioners across a range of healthcare settings are often on the front line for care and support for older client populations. It is anticipated that the findings of this study will provide the mechanism through which mental health nurses and practitioners who encounter older populations 
can gain a greater understanding of the impact of intimate partner violence and the needs of older women from the perspective of older women themselves. Ultimately this has the potential to improve the effectiveness of care provision and support. The findings presented in this paper have the capacity to be a powerful tool for practitioners and especially nurses and other professionals working in mental health settings. Particularly where older women may present as a result of their experiences of IPV, but are not always be recognised as such due to the disjuncture between professional dialogue and personal narrative as identified in the present study. Finally as highlighted by Humphreys and Thiara more broadly (2003):

"Women have a great deal to lose and little to gain if mental health services are insensitive to their needs and the role of trauma and abuse in creating their emotional problems" (p223).

\section{Acknowledgements}

We would like thank all of the women who agreed to take part in the workshop. The artefacts created during the workshop have informed the development of an e-learning resource and we would like to thank the funders for supporting the development of this resource. 


\section{References}

Band-Winterstein T \& Eisikovits Z (2010): Towards phenomenological theorizing about old women abuse. Ageing International 35, 202-214.

Beaulaurier RL, Seff LR, Newman FL \& Dunlop B (2006): Internal barriers to help seeking for middle-aged and older women who experience intimate partner violence. Journal of Elder Abuse \& Neglect 17, 53-74.

Bryman, A. (2004). Quantity and Quality in Social Research. London: Routledge.

Buchbinder E \& Winterstein T (2003): "Like a wounded bird": Older battered women's life experiences with intimate violence. Journal of Elder Abuse \& Neglect 15, 23-44.

Crawford, P., Brown, B., Baker, C., Tischler, V., Abrams, B. (2015) Health Humanities. Palgrave Macmillan: Basingstoke Dutton MA, Green BL, Kaltman SI, Roesch DM, Zeffiro TA \& Krause ED (2006):

Intimate partner violence, PTSD, and adverse health outcomes. Journal of Interpersonal Violence 21, 955-968.

Ellsberg M, Jansen HA, Heise L, Watts CH \& Garcia-Moreno C (2008): Intimate partner violence and women's physical and mental health in the WHO multi 
country study on women's health and domestic violence: an observational study.

The Lancet 371, 1165-1172.

Fagan, K. (2016) http://www.kevinfegan.co.uk/2013/biography.htm (accessed 24.11.16)

Faulkner, S (2009) Poetry as method: Reporting research through verse. Walnut Creek CA: Left Coast Press

Foster, V. (2007) 'Ways of knowing and showing': imagination and representation in feminist participatory social research. Journal of Social Work Practice. 21:3, 361-376

Frank, A (2013) The Wounded Storyteller: Body, Illness and Ethics $2^{\text {nd }}$ Ed. The University of Chicago Press: London

Gray, M., Agllias, K., Schbert, L. (2015) Doctoral research from a feminist perspective: Acknowledging, advancing and aligning Women's experience. Qualitative Social Work 14(6), 758-775

Hightower J, Smith M \& Hightower H (2006): Hearing the voices of abused older women. Journal of Gerontological Social Work 46, 205-227.

Humphreys C \& Thiara R (2003): Mental health and domestic violence:'I call it symptoms of abuse'. British Journal of Social Work 33, 209-226.

Lazenbatt A \& Devaney J (2014): Older women living with domestic

violence: coping resources and mental health and wellbeing. Current Nursing 
Journal 1, 10-22.

Leavy, P. (2015) Method meets Art. Arts Based Research Practice. New York: Guilford.

Lundy, M. \& Grossman, S. (2009) Domestic violence service users: a comparison of older and younger women victims. Journal of Family Violence. 24, 297 - 309

McGarry J, Ali P and Hincliff S, 2016. Older women, intimate partner violence and mental health: a consideration of the particular issues for health and health care practice Journal of Clinical Nursing. (In Press.)

McGarry J, Simpson C \& Mansour M (2010): How domestic abuse affects the wellbeing of older women. Nursing Older People 22, 33-37.

Nägele B, Bohm U, Toth O \& Goergen T (2010) Intimate Partner Violence and Older Women: Summary Report. Gottingen. Available from: https://www. frauen-gegen-gewalt. de/literaturtipps-262. html.

Nilsson, A., Fältholm, Y., Abrahamsson, L. (2010) Reframing practice through the use of Personas. Reflective Practice 11, 285-298

Ouimet, D. Emerging from Broken) http://emergingfrombroken.com/about-us/ (accessed 25.08.16)

SafeLives. (2016) Safe Later Lives: Older people and domestic absue. Report: Safelives

http://safelives.org.uk/sites/default/files/resources/Safe\%20Later\%20Liv 
es\%20-\%200lder\%20people\%20and\%20domestic\%20abuse.pdf (accessed 27.4.17)

Scott M, McKie L, Morton S, Seddon E \& Wosoff F (2004): Older women and domestic violence in Scotland... and for 39 years I got on with it. Edinburgh:

Health Scotland.

Trevillion K, Oram S, Feder G \& Howard LM (2012): Experiences of domestic violence and mental disorders: a systematic review and meta-analysis. PLoS ONE 7, e51740.

World Health Organisation (2012) Understanding and addressing violence against women

http://apps.who.int/iris/bitstream/10665/77432/1/WHO RHR 12.36 eng.pdf (accessed 27.1.17) 